\title{
Nonaneurysmal Perimesencephalic Hemorrhage Is Associated with Deep Cerebral Venous Drainage Anomalies: A Systematic Literature Review and Meta-Analysis
}

\author{
(D)A. Rouchaud, (D).T. Lehman, (D) M.H. Murad, (D)A. Burrows, DH.J. Cloft, (DE.P. Lindell, DD.F. Kallmes, and (DW. Brinjikji
}

\begin{abstract}
BACKGROUND AND PURPOSE: Mechanisms underlying bleeding in nonaneurysmal perimesencephalic SAH remain unclear. Previous investigators have suggested a relationship between nonaneurysmal perimesencephalic SAH and primitive venous drainage of the basal vein of Rosenthal. We performed a meta-analysis to evaluate the relation between primitive basal vein of Rosenthal drainage and nonaneurysmal perimesencephalic SAH.
\end{abstract}

MATERIALS AND METHODS: We performed a comprehensive literature search of all studies examining the prevalence of primitive basal vein of Rosenthal drainage in patients with aneurysmal SAH and nonaneurysmal perimesencephalic SAH. Data collected were primitive basal vein of Rosenthal drainage (direct connection of perimesencephalic veins into the dural sinuses instead of the Galenic system) in at least 1 cerebral hemisphere, normal bilateral basal vein of Rosenthal drainage systems, and the number of overall primitive venous systems in the nonaneurysmal perimesencephalic SAH and aneurysmal SAH groups. Statistical analysis was performed by using a random-effects meta-analysis.

RESULTS: Eight studies with 888 patients (334 with nonaneurysmal perimesencephalic SAH and 554 with aneurysmal SAH) and 1657 individual venous systems were included. Patients with nonaneurysmal perimesencephalic SAH were more likely to have a primitive basal vein of Rosenthal drainage in at least 1 hemisphere (47.7\% versus $22.1 \%$; OR, 3.31; 95\% Cl, 2.15-5.08; $P<.01$ ) and were less likely to have bilateral normal basal vein of Rosenthal drainage systems than patients with aneurysmal SAH (18.3\% versus $37.4 \%$; OR, $0.27 ; 95 \% \mathrm{Cl}$, $0.14-0.52 ; P<.01)$. When we considered individual venous systems, there were higher rates of primitive venous systems in patients with nonaneurysmal perimesencephalic SAH than in patients with aneurysmal SAH (34.9\% versus 15.3\%; OR, 3.90; 95\% Cl, 2.37-6.43; $P<.01$ ).

CONCLUSIONS: Patients with nonaneurysmal perimesencephalic SAH have a higher prevalence of primitive basal vein of Rosenthal drainage in at least 1 hemisphere than patients with aneurysmal SAH. This finding suggests a venous origin of some nonaneurysmal perimesencephalic SAHs. A primitive basal vein of Rosenthal pattern is an imaging finding that has the potential to facilitate the diagnosis of nonaneurysmal perimesencephalic SAH.

ABBREVIATIONS: aSAH = aneurysmal subarachnoid hemorrhage; BVR = basal vein of Rosenthal; NAPH = nonaneurysmal perimesencephalic subarachnoid hemorrhage

$\mathbf{N}$ onaneurysmal perimesencephalic subarachnoid hemorrhage (NAPH) represents approximately $10 \%-15 \%$ of all spontaneous SAH cases. ${ }^{1-5}$ NAPHs are characterized by the ab-

Received October 14, 2015; accepted after revision February 9, 2016.

From the Departments of Radiology (A.R., V.TL., H.J.C., E.P.L., D.F.K., W.B.), Preventive Medicine and Center for the Science of Healthcare Delivery (M.H.M.), and Neurosurgery (A.B.)., Mayo Clinic, Rochester, Minnesota.

Please address correspondence to Aymeric Rouchaud, MD, Department of Radiology, Mayo Clinic, 200 First St SW, Rochester, MN 55905; e-mail: aymeric.rouchaud@gmail.com

三 Indicates article with supplemental on-line table.

Indicates article with supplemental on-line photo.

Evidence-Based Medicine Level 2.

http://dx.doi.org/10.3174/ajnr.A4806 sence of an aneurysm or other source of bleeding on 4-vessel digital subtraction angiography and subarachnoid blood located predominantly in the perimesencephalic cistern (Fig 1). ${ }^{1,6-17}$ The prognosis for NAPH is usually much better than that of aneurysmal subarachnoid hemorrhage (aSAH), with a benign clinical course and low risk of rebleeding or vasospasm. ${ }^{13,16,18-21}$

The cause and the mechanisms of bleeding have yet to be established. Many different sources of bleeding have been proposed, including microaneurysm or microangioma, rupture of pontine perforating arteries, bleeding from perimesencephalic or deep internal veins, or hemorrhage from basilar trunk dissections and intramural hematoma. ${ }^{13,22-35}$

Other studies have suggested a possible link between abnormal drainage of the basal vein of Rosenthal (BVR) and NAPH. ${ }^{33,36-41}$ 
Because of the rarity of this pathology, most series reporting BVR drainage in patients with NAPH are small retrospective single-center case series. Thus, the exact link between abnormal BVR drainage and NAPH has yet to be established. Because of this lack of information, we performed a systematic review and metaanalysis of studies examining BVR drainage patterns in patients with NAPH compared with those with aSAH. The deep cerebral venous drainage patterns are classified as the following: Type A or "normal continuous," in which the basal vein of Rosenthal is continuous with the deep middle cerebral vein and drains mainly into the vein of Galen; Type B or "normal discontinuous," in which there is discontinuous dual drainage, both anterior to the uncal veins and posterior to the vein of Galen; and Type C or "primitive," which drains directly into the dural sinuses instead of the
Galenic system. Types A and B are considered normal variant patterns, whereas Type $\mathrm{C}$ or primitive venous drainage is considered abnormal. ${ }^{33,40}$ Illustrations of the 3 drainage patterns are provided in Fig 2.

\section{MATERIALS AND METHODS \\ Literature Search}

We identified all studies published between 1980 and September 2015 that reported BVR drainage in patients with NAPH and aSAH. A comprehensive literature search of the data bases PubMed, Ovid MEDLINE, and Ovid EMBASE was designed and conducted by an experienced librarian with input from the authors. The key words "perimesencephalic," "subarachnoid hemorrhage," "basal vein," "Rosenthal," and "drainage" were used in both "AND" and "OR" combinations.

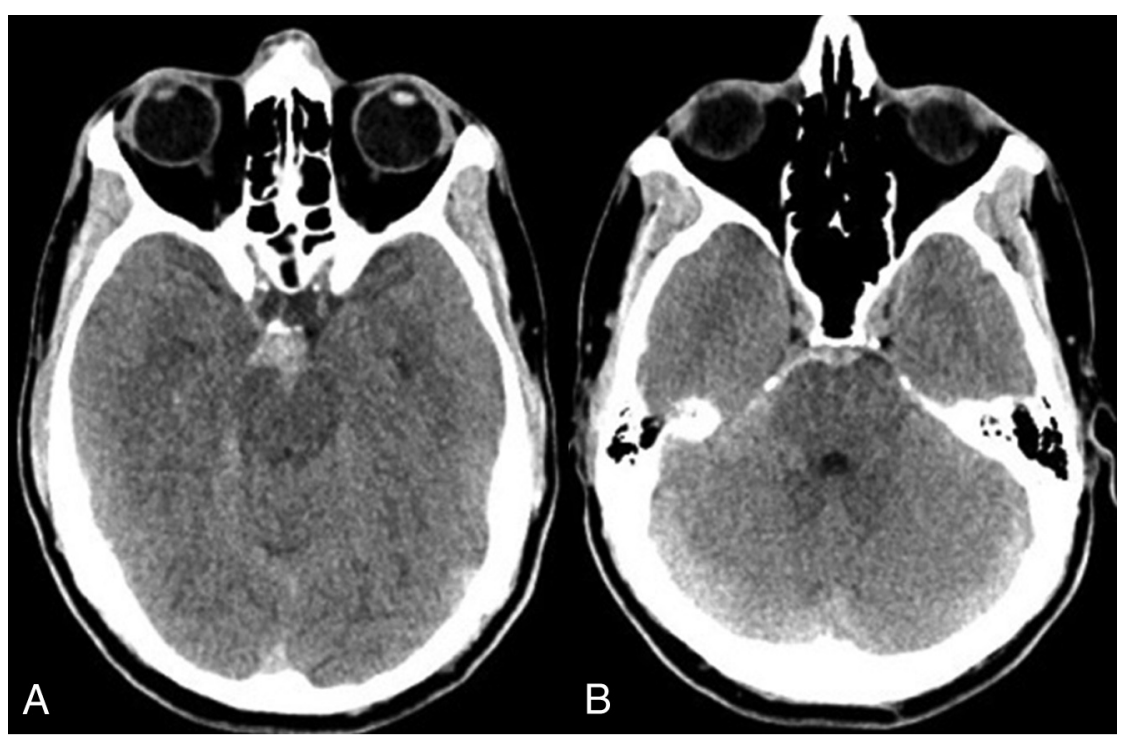
Studies were selected by using the following criteria: 1) NAPH, 2) involving subjects 18 years of age or older, 3 ) with available data on venous drainage by using the above-defined criteria, 4) comparing venous drainage to patients with aneurysmal $\mathrm{SAH}, 5)$ retrospective or prospective studies with at least 3 patients, and 6) published in English.

Two authors separately searched the data base and selected potentially relevant articles based on the title and abstract and obtained the full text for detailed review. We also searched the reference lists of retrieved articles and published review articles for additional studies. We screened duplicate publications that drew on the same datasets (ie, data overlapping with those in other included studies). In duplicate publications, only those with the most complete data were included. The included stud-

FIG 1. Pattern of nonaneurysmal perimesencephalic hemorrhage. Nonaneurysmal perimesencephalic hemorrhage in a 54-year-old man with a headache after sneezing. The CT demonstrates blood isolated to the perimesencephalic cistern with some extension into the right ambient cistern. No blood is seen in the bilateral Sylvian fissures, and there was no intraventricular hemorrhage.

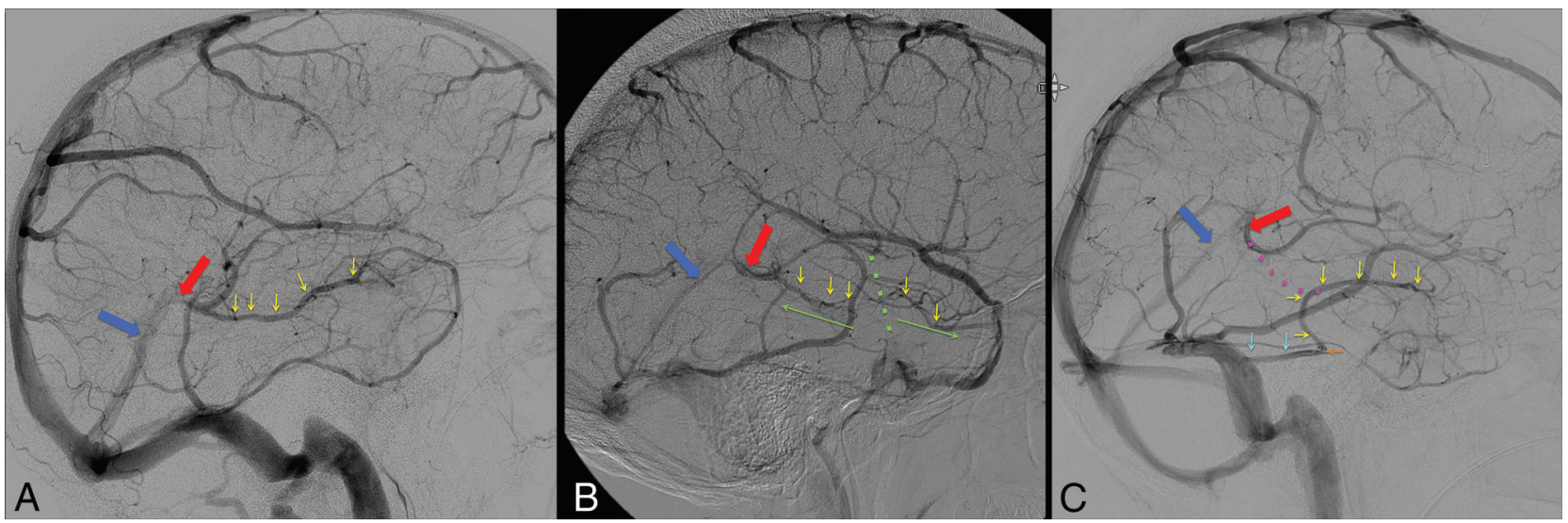

FIG 2. Lateral venous phase DSA images illustrating the different variants of the basal vein of Rosenthal: BVR (yellow arrows), vein of Galen (red arrow), and straight sinus (dark blue arrow). A, Type $\mathrm{A}$ (normal continuous pattern). The BVR is continuous and drains mainly posteriorly into the vein of Galen. B, Type B (normal discontinuous pattern). Discontinuous dual drainage of the BVR anterior into the cavernous sinus via the uncal vein and posterior to the vein of Galen. The green dotted line and the 2 green arrows illustrate anterior and posterior drainage. $C$, Type $C$ (primitive pattern). BVR drains into veins (the uncal, anterior pontomesencephalic, or lateral mesencephalic veins or the tentorial sinus) other than the vein of Galen. The anterior segment of the BVR (yellow arrow) drains into the lateral mesencephalic vein to the petrosal sinus (light blue arrows), ultimately into the sigmoid sinus. The middle and posterior segments are absent (normal course is illustrated by the pink dotted line). 


\begin{tabular}{lcccccc}
\hline Meta-analysis: comparison of BVR drainage patterns in patients with NAPH versus aSAH \\
\hline & $\begin{array}{c}\text { Nonaneurysmal } \\
\text { Perimesencephalic } \\
\text { Hemorrhage }\end{array}$ & $\begin{array}{c}\text { Aneurysmal } \\
\text { Subarachnoid } \\
\text { Hemorrhage }\end{array}$ & OR & $P$ Value & I $^{2}$ \\
\hline $\begin{array}{c}\text { Patients with at least 1 } \\
\text { primitive BVR drainage } \\
\text { pattern }\end{array}$ & $47.7 \%(148 / 310)$ & $22.1 \%(75 / 340)$ & $3.31(2.15-5.08)$ & $<.01$ & $29 \%$ \\
$\begin{array}{c}\text { Patients with normal } \\
\text { bilateral BVR drainage } \\
\text { pattern }\end{array}$ & $18.3 \%(61 / 334)$ & $37.4 \%(207 / 554)$ & $0.27(0.14-0.52)$ & $<.01$ & $57 \%$ \\
$\begin{array}{c}\text { Abnormal BVR drainage by } \\
\text { venous system }\end{array}$ & $34.9 \%(220 / 630)$ & $15.3 \%(157 / 1027)$ & $3.90(2.37-6.43)$ & $<.01$ & $70 \%$ \\
\hline
\end{tabular}

\section{RESULTS}

\section{Literature Review}

The initial literature search yielded 243 articles. On initial abstract and title review, 221 were excluded because they were deemed not relevant to our study. Full texts of the remaining 22 articles were retrieved. Of these, 14 were excluded because they were either case reports, review articles, or did not provide data on the predefined study outcomes.

In total, 8 studies with 334 patients

ies reported the definition of NAPH with homogeneity as an accumulation of subarachnoid blood predominantly in the perimesencephalic cisterns with the center of the hemorrhage located in front of the mesencephalon without blood in the interhemispheric and lateral Sylvian fissures (except minute amounts) and no important intraventricular hemorrhage (Fig 1), ${ }^{1}$ and absence of an aneurysm or other source of bleeding identified on arterial imaging including DSA. All the studies reported the venous drainage patterns on diagnostic cerebral angiography according to the 3 grades previously described as Type A (normal continuous), in which the BVR is continuous with the deep middle cerebral vein and drains mainly into the vein of Galen; Type B (normal discontinuous), in which there is discontinuous venous drainage anterior to the uncal vein and posterior to the vein of Galen; and Type $\mathrm{C}$ (primitive variant), in which there is drainage mainly to veins other than the vein of Galen. These include perimesencephalic veins draining into the superior petrosal sinus or the BVR draining directly into the transverse or straight sinus. ${ }^{33,40}$ Illustrations of the 3 drainage patterns are provided in Fig 2.

Data were extracted independently by 2 authors by using a standardized form, and any disagreement was resolved by consensus. We did not contact the authors of the studies to request incomplete or unpublished data. For each study, we extracted the following data: patient demographics, number patients with at least 1 primitive (Type C) BVR drainage pattern, number of patients with a Type A bilateral BVR drainage pattern, and number of venous systems with primitive (Type C) drainage. Comparisons were performed between patients with NAPH versus those with aSAH.

\section{Statistical Analysis}

All included studies were comparative. Meta-analysis results were expressed as an odds ratio for binary outcomes by using a random-effects meta-analysis. ${ }^{42}$ For all outcomes, we quantified between-study heterogeneity by creating forest plots and calculating the $\mathrm{I}^{2}$ statistic. ${ }^{43}$ We explored the impact of publication bias by constructing funnel plots and testing their symmetry with the Egger test.

\section{Risk-of-Bias Assessment}

Risk-of-bias assessment was performed by using the NewcastleOttawa Scale. This tool is used for assessing the risk of bias of nonrandomized studies included in systematic reviews or metaanalyses. Each study is judged on 8 items categorized into 3 groups: 1) selection of the study groups, 2) comparability of the study groups, and 3) ascertainment of the outcome of interest. ${ }^{44}$ with NAPH and 554 with aSAH were included. The definition of NAPH was similar between studies. This total represented 1657 individual venous systems. A summary of included studies is provided in the On-line Table. Of the 334 patients with NAPH, 61 (18.3\%) had normal (Type A) bilateral BVR drainage and 166 (49.7\%) had primitive (Type C) BVR drainage in at least 1 hemisphere. Of the 630 venous systems analyzed in patients with NAPH, 220 (34.9\%) were abnormal (Type C). Of the 554 patients with aSAH, 207/554 (37.4\%) had normal (Type A) bilateral BVR drainage and 75/340 (22.1\%) had primitive (Type C) BVR drainage in at least 1 hemisphere. Of the 1027 venous systems analyzed in patients with aSAH, 157 (15.3\%) were abnormal (Type C).

\section{Venous Drainage Pattern in Patients with NAPH versus Those with aSAH}

Patients with NAPH had lower rates of normal bilateral BVR drainage than those with aSAH ( $18.3 \%$ versus $37.4 \%$; OR, 0.27 ; 95\% CI, $0.14-0.52 ; P<.01)$ but higher rates of the primitive BVR drainage pattern in at least 1 hemisphere $(47.7 \%$ versus 22.1\%; OR, 3.31; 95\% CI, 2.15-5.08; $P<.01$ ). Considered individually, there were higher rates of abnormal venous systems in patients with NAPH than in those with aSAH $(34.9 \%$ versus $15.3 \%$ ) with an odds ratio of 3.90 (95\% CI, 2.37-6.43; $P<.01)$. These data are summarized in the Table. Forest plots are provided in Fig $3 A-C$.

\section{Risk of Bias}

All studies had a low risk of bias. In all studies, the NAPH and aSAH groups were selected from a consecutive series of patients with angiographically confirmed presence or absence of intracranial aneurysm. Venous drainage patterns were assessed by using diagnostic cerebral angiography in all cases. Study groups were comparable, with no significant differences in baseline characteristics between groups. The ascertainment of the outcome of interest was satisfactory in all studies because readers were blinded to the nature of the patients' SAHs.

$\mathrm{I}^{2}$ values for meta-analysis demonstrated fair homogeneity for the outcome "patients with at least 1 primitive BVR drainage pattern" ( $\mathrm{I}^{2}$ statistics $=29 \%$ ) and substantial heterogeneity for the outcomes "patients with a normal bilateral BVR drainage pattern" ( $\mathrm{I}^{2}$ statistics $\left.=57 \%\right)$ and "abnormal BVR drainage by venous system" ( $\mathrm{I}^{2}$ statistics $\left.=70 \%\right)$.

No evidence of publication bias was observed on the basis of the Egger test ( $P>.05$ for all 3 outcomes). Funnel plots are provided in On-line Fig 1. 


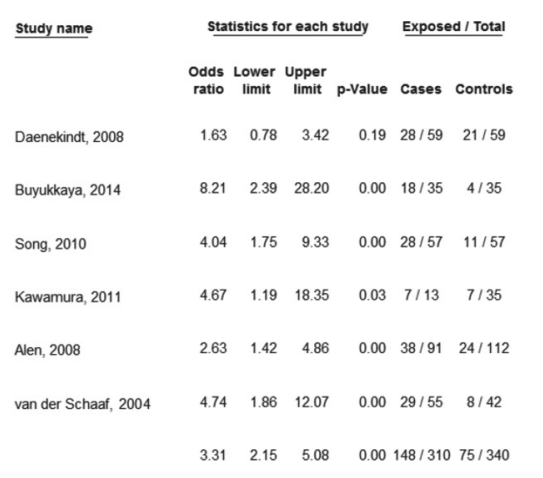

\begin{tabular}{|c|c|c|c|c|c|c|}
\hline Daenekindt, 2008 & 1.63 & 0.78 & 3.42 & 0.19 & $28 / 59$ & $21 / 59$ \\
\hline Buyukkaya, 2014 & 8.21 & 2.39 & 28.20 & 0.00 & $18 / 35$ & $4 / 35$ \\
\hline Song, 2010 & 4.04 & 1.75 & 9.33 & 0.00 & $28 / 57$ & $11 / 57$ \\
\hline Kawamura, 2011 & 4.67 & 1.19 & 18.35 & 0.03 & $7 / 13$ & $7 / 35$ \\
\hline Alen, 2008 & 263 & 1.42 & 4.86 & 0.00 & $38 / 91$ & $24 / 112$ \\
\hline van der Schaaf, 2004 & 4.74 & 1.86 & 12.07 & 0.00 & $29 / 55$ & $8 / 42$ \\
\hline & 3.31 & 2.15 & 5.08 & 0.00 & $148 / 310$ & $75 / 340$ \\
\hline
\end{tabular}
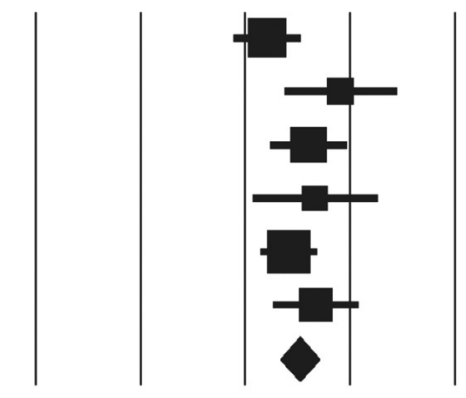

Isquared 29\%

0.01

0.1

$10 \quad 100$

A

\begin{tabular}{|c|c|c|c|c|c|c|}
\hline \multirow[t]{2}{*}{ Study name } & \multicolumn{4}{|c|}{ Statistics for each study } & \multicolumn{2}{|c|}{ Exposed / Total } \\
\hline & $\begin{array}{l}\text { Odds } \\
\text { ratio }\end{array}$ & $\begin{array}{l}\text { Lower } \\
\text { limit }\end{array}$ & $\begin{array}{l}\text { Upper } \\
\text { limit }\end{array}$ & p-value & Cases & Controls \\
\hline Daenekindt, 2008 & 1.38 & 0.55 & 3.47 & 0.49 & $13 / 59$ & $10 / 59$ \\
\hline Yamakawa, 2008 & 0.31 & 0.07 & 1.44 & 0.14 & $2 / 18$ & $32 / 112$ \\
\hline Buyukkaya, 2014 & 0.23 & 0.08 & 0.64 & 0.00 & $14 / 35$ & $26 / 35$ \\
\hline Song, 2010 & 0.26 & 0.12 & 0.58 & 0.00 & $16 / 57$ & $34 / 57$ \\
\hline Kawamura, 2011 & 0.05 & 0.00 & 1.00 & 0.05 & $0 / 13$ & $14 / 35$ \\
\hline Alen, 2008 & 0.16 & 0.08 & 0.33 & 0.00 & $12 / 91$ & $54 / 112$ \\
\hline Watanabe, 2002 & 0.28 & 0.01 & 5.07 & 0.39 & $0 / 6$ & $22 / 102$ \\
\hline van der Schaaf, 2004 & 0.14 & 0.04 & 0.47 & 0.00 & $4 / 55$ & $15 / 42$ \\
\hline & 0.27 & 0.14 & 0.52 & 0.00 & $61 / 334$ & $4207 / 554$ \\
\hline
\end{tabular}

I squared $57 \%$

B

\begin{tabular}{|c|c|c|c|c|c|c|}
\hline \multirow[t]{2}{*}{ Study name } & \multicolumn{4}{|c|}{ Statistics for each study } & \multicolumn{2}{|c|}{ Exposed / Total } \\
\hline & $\begin{array}{l}\text { Odds } \\
\text { ratio }\end{array}$ & $\begin{array}{c}\text { Lower } \\
\text { limit }\end{array}$ & $\begin{array}{c}\text { Upper } \\
\text { limit }\end{array}$ & p-Value & Cases & Controls \\
\hline Daenekindt, 2008 & 1.16 & 0.64 & 2.10 & 0.63 & $32 / 115$ & $27 / 108$ \\
\hline Yamakawa, 2008 & 7.92 & 3.58 & 17.50 & 0.00 & $18 / 35$ & $23 / 195$ \\
\hline Buyukkaya, 2014 & 6.78 & 2.41 & 19.09 & 0.00 & $24 / 70$ & $5 / 70$ \\
\hline Song, 2010 & 4.36 & 2.18 & 8.72 & 0.00 & $41 / 114$ & $13 / 114$ \\
\hline Kawamura, 2011 & 5.71 & 1.87 & 17.50 & 0.00 & $10 / 25$ & $7 / 67$ \\
\hline Alen, 2008 & 2.48 & 1.48 & 4.16 & 0.00 & $47 / 149$ & $31 / 198$ \\
\hline Watanabe, 2002 & 4.97 & 1.50 & 16.45 & 0.01 & $7 / 12$ & $42 / 191$ \\
\hline van der Schaaf, 2004 & 4.95 & 2.24 & 10.93 & 0.00 & $41 / 110$ & $9 / 84$ \\
\hline & 3.90 & 2.37 & 6.43 & 0.00 & $220 / 630$ & $157 / 1027$ \\
\hline
\end{tabular}

I squared $70 \%$

C

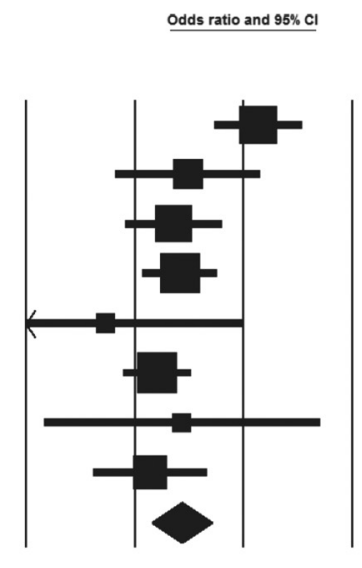

0.01

0.1

Odds ratio and $95 \% \mathrm{Cl}$

\section{Odds ratio and $95 \% \mathrm{CI}$}

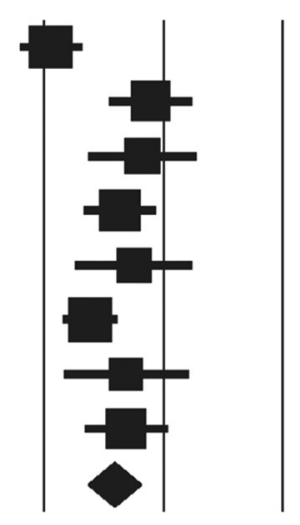

0.1

1

10

100

FIG 3. Meta-analyses. $A$, Comparison of the proportion of patients with at least 1 primitive BVR drainage. $B$, Comparison of the proportion of patients with a normal bilateral BVR drainage pattern. C, Comparison of the proportion of abnormal BVR drainage by the venous system.

\section{DISCUSSION}

Our meta-analysis demonstrated that patients with NAPH were more likely to have primitive BVR drainage in at least 1 hemisphere and were less likely to have bilateral normal BVR drainage systems. Regarding individual venous systems, there were higher rates of abnormal venous systems in patients with NAPHs than in those with aSAH. Overall, these findings suggest that the occurrence of some NAPHs is associated with the primitive drainage pattern of the BVR. While the diagnosis of NAPH is still a diagnosis of exclusion, the radiologic identification of a primitive 
drainage pattern in case of SAH could help affirm the diagnosis of $\mathrm{NAPH}$ in some cases.

The deep venous system of the brain is composed of the internal cerebral vein, the great vein of Galen, the BVR, and their respective tributaries. ${ }^{45,46}$ Anatomically, the BVR begins just anterior to the midbrain near the anterior perforated substance, runs around the brain stem, and terminates posteriorly, usually into the Galenic system via the great vein of Galen. ${ }^{47}$ The BVR may also drain into the straight sinus or the internal cerebral veins. Embryologically, the BVR is not one of the original pial veins but is rather a secondary vessel formed by longitudinal anastomoses of 3 primitive veins during development: the telencephalic, diencephalic, and mesencephalic veins. ${ }^{48}$ In the early embryonic stage, these primitive veins drain into the tentorial sinuses. Later, many channels draining into the tentorial sinus usually spontaneously obliterate with a secondarily posteromedial and superior drainage of the BVR into the Galenic venous system via the anastomotic channels. However, discontinuity due to maldevelopment of longitudinal anastomoses of the 3 primitive veins during the embryologic stages could lead to posterolateral and inferior drainage of the BVR into the transverse sinus via the tentorial sinus as a more primitive form. ${ }^{47-50}$

This meta-analysis confirms that compared with patients with aSAH, those with NAPH had more primitive forms of the BVR, including primitive venous drainage directly into dural sinuses (the cavernous sinus via the uncal vein, the superior petrosal sinus via the tentorial sinus, or the perimesencephalic vein) instead of into the Galenic system. ${ }^{33,36,38}$ These findings suggest that the primitive drainage pattern of the BVR is a risk factor for NAPH in some cases. ${ }^{39}$ There are a number of reasons why a primitive venous pattern could be associated with NAPH. The direct connection of perimesencephalic veins with the dural sinuses may predispose to sudden increases in venous pressure with engorgement and rupture of the veins as a result. ${ }^{33,36,39}$ Intracranial venous congestion caused by straining might tear a vein fixed to a dural sinus or cause abrupt swelling of the tributaries of the BVR in patients with the primitive pattern. ${ }^{1,33,51}$ Any stimulus similar to the Valsalva maneuver increases intrathoracic pressure, which blocks the internal jugular venous return and results in elevated intracranial venous pressure or mechanical swelling of intracranial veins and potentially leads to venous or capillary breakdown. ${ }^{39}$ In addition, some of the primitive veins circulate across the tentorial margin, exposing them to torsion or friction and making them even more prone to rupture where they cross the tentorial margin. ${ }^{1,51}$

Lending further support to the idea that this anatomic variant is a potential culprit in NAPH is a study by van der Schaaff et al, ${ }^{38}$ which demonstrated that in patients with unilateral primitive drainage, blood primarily extravasated on the side of the primitive drainage. The BVR caliber may also have an etiologic role in patients who experience NAPH as suggested by Buyukkaya et al, ${ }^{41}$ who identified a relationship between low-calibration BVR and NAPH in patients with normal drainage patterns. However, if aberrant drainage patterns are somehow linked to NAPH, it is surprising that the incidence of rebleeding is very low because anatomic venous drainage patterns are not likely to change after bleeding. ${ }^{52-56}$ However, this low rebleeding rate could be ex- plained by spontaneous healing of the venous rupture by fibrous tissue reaction, which could reinforce the wall of the vein, as speculated by Matsumaru et al. ${ }^{33,51}$

\section{Strengths and Limitations}

The strengths of this study include following a protocol established a priori, a comprehensive literature search that involved multiple databases, and the process of study selection performed by independent reviewers. The main limitation of this analysis is that most studies did not include a control group of patients without hemorrhage. Thus, we could not determine whether patients with NAPH are more likely than healthy controls to have abnormal venous drainage patterns. $\mathrm{I}^{2}$ values for meta-analysis demonstrated fair homogeneity for the outcome "patients with at least 1 primitive BVR drainage pattern" and substantial heterogeneity for the outcomes "patients with normal bilateral BVR drainage pattern" and "abnormal BVR drainage by venous system," which could affect the results of our meta-analysis. Publication bias is a limitation of many meta-analyses. However, we did not detect any publication bias based on funnel plots and Egger tests.

\section{CONCLUSIONS}

$\mathrm{NAPH}$ is associated with the presence of a primitive variant pattern of BVR drainage with direct connection of perimesencephalic veins in the dural sinuses in at least 1 hemisphere. These results support a venous origin of some NAPHs. A primitive BVR pattern could represent an imaging argument to affirm the diagnosis of NAPH in some cases.

Disclosures: David F. Kallmes—UNRELATED: Consultancy: Medtronic, ${ }^{\star}$ Comments: steering committee of a clinical trial; Grants/Grants Pending: MicroVention, ${ }^{*}$ Sequent Medical, ${ }^{\star}$ Surmodics, ${ }^{*}$ Codman, ${ }^{*}$ Medtronic, ${ }^{*}$ NeuroSigma, ${ }^{\star}$ Comments: preclinical research and clinical trials; Travel/Accommodations/Meeting Expenses Unrelated to Activities Listed: Medtronic,* Comments: presentation at FDA panel meeting. *Money paid to the institution.

\section{REFERENCES}

1. van Gijn J, van Dongen KJ, Vermeulen M, et al. Perimesencephalic hemorrhage: a nonaneurysmal and benign form of subarachnoid hemorrhage. Neurology 1985;35:493-97 CrossRef Medline

2. Farrés MT, Ferraz-Leite H, Schindler E, et al. Spontaneous subarachnoid hemorrhage with negative angiography: CT findings. J Comput Assist Tomogr 1992;16:534-37 CrossRef Medline

3. Ferbert A, Hubo I, Biniek R. Non-traumatic subarachnoid hemorrhage with normal angiogram: long-term follow-up and CT predictors of complications. J Neurol Sci 1992;107:14-18 CrossRef Medline

4. Pinto AN, Ferro JM, Canhao P, et al. How often is a perimesencephalic subarachnoid haemorrhage CT pattern caused by ruptured aneurysms? Acta Neurochir (Wien) 1993;124:79-81 CrossRef Medline

5. Boswell S, Thorell W, Gogela S, et al. Angiogram-negative subarachnoid hemorrhage: outcomes data and review of the literature. $J$ Stroke Cerebrovasc Dis 2013;22:750-57 CrossRef Medline

6. Alén JF, Lagares A, Lobato RD, et al. Comparison between perimesencephalic nonaneurysmal subarachnoid hemorrhage and subarachnoid hemorrhage caused by posterior circulation aneurysms. J Neurosurg 2003;98:529-35 CrossRef Medline

7. Brismar J, Sundbärg G. Subarachnoid hemorrhage of unknown origin: prognosis and prognostic factors. J Neurosurg 1985;63: 349-54 CrossRef Medline

8. Cioffi F, Pasqualin A, Cavazzani P, et al. Subarachnoid haemorrhage of unknown origin: clinical and tomographical aspects. Acta Neurochir (Wien) 1989;97:31-39 CrossRef Medline 
9. Eskesen V, Sorensen EB, Rosenorn J, et al. The prognosis in subarachnoid hemorrhage of unknown etiology. J Neurosurg 1984;61: 1029-31 CrossRef Medline

10. Gomez PA, Lobato RD, Rivas JJ, et al. Subarachnoid haemorrhage of unknown aetiology. Acta Neurochir (Wien) 1989;101:35-41 CrossRef Medline

11. Nishioka H, Torner JC, Graf CJ, et al. Cooperative study of intracranial aneurysms and subarachnoid hemorrhage: a long-term prognostic study, III: subarachnoid hemorrhage of undetermined etiology. Arch Neurol 1984;41:1147-51 CrossRef Medline

12. Ronkainen A, Hernesniemi J. Subarachnoid haemorrhage of unknown aetiology. Acta Neurochir (Wien) 1992;119:29-34 CrossRef Medline

13. Schwartz TH, Solomon RA. Perimesencephalic nonaneurysmal subarachnoid hemorrhage: review of the literature. Neurosurgery 1996;39:433-40; discussion 440 CrossRef Medline

14. Velthuis BK, Rinkel GJ, Ramos LM, et al. Perimesencephalic hemorrhage: exclusion of vertebrobasilar aneurysms with CT angiography. Stroke 1999;30:1103-09 CrossRef Medline

15. Rinkel GJ, Wijdicks EF, Vermeulen M, et al. Nonaneurysmal perimesencephalic subarachnoid hemorrhage: CT and MR patterns that differ from aneurysmal rupture. AJNR Am J Neuroradiol 1991; 12:829-34 Medline

16. Van Calenbergh F, Plets C, Goffin J, et al. Nonaneurysmal subarachnoid hemorrhage: prevalence of perimesencephalic hemorrhage in a consecutive series. Surg Neurol 1993;39:320-23 CrossRef Medline

17. Brinjikji W, Kallmes DF, White JB, et al. Inter- and intraobserver agreement in CT characterization of nonaneurysmal perimesencephalic subarachnoid hemorrhage. AJNR Am J Neuroradiol 2010; 31:1103-05 CrossRef Medline

18. Canhão P, Ferro JM, Pinto AN, et al. Perimesencephalic and nonperimesencephalic subarachnoid haemorrhages with negative angiograms. Acta Neurochir (Wien) 1995;132:14-19 CrossRef Medline

19. Rinkel GJ, Wijdicks EF, Hasan D, et al. Outcome in patients with subarachnoid haemorrhage and negative angiography according to pattern of haemorrhage on computed tomography. Lancet 1991; 338:964-68 CrossRef Medline

20. Cruz JP, Sarma D, Noel de Tilly L. Perimesencephalic subarachnoid hemorrhage: when to stop imaging? Emerg Radiol 2011;18:197-202 CrossRef Medline

21. Jung JY, Kim YB, Lee JW, et al. Spontaneous subarachnoid haemorrhage with negative initial angiography: a review of 143 cases. J Clin Neurosci 2006;13:1011-17 CrossRef Medline

22. Boukobza M, Crassard I, Bousser MG, et al Radiological findings in cerebral venous thrombosis presenting as subarachnoid hemorrhage: a series of 22 cases. Neuroradiology 2016;58:11-16 CrossRef Medline

23. Mathews MS, Brown D, Brant-Zawadzki M. Perimesencephalic nonaneurysmal hemorrhage associated with vein of Galen stenosis. Neurology 2008;70:2410-11 CrossRef Medline

24. Oda S, Shimoda M, Hoshikawa K, et al. Cortical subarachnoid hemorrhage caused by cerebral venous thrombosis. Neurol Med Chir (Tokyo) 2011;51:30-36 CrossRef 21273741

25. Schievink WI, Wijdicks EF. Origin of pretruncal nonaneurysmal subarachnoid hemorrhage: ruptured vein, perforating artery, or intramural hematoma? Mayo Clin Proc 2000;75:1169-73 CrossRef Medline

26. Bohmfalk GL, Story JL. Intermittent appearance of a ruptured cerebral aneurysm on sequential angiograms: case report. J Neurosurg 1980;52:263-65 CrossRef Medline

27. Crawford JV, Russell DS. Cryptic arteriovenous and venous hamartomas of the brain. J Neurol Neurosurg Psychiatry 1956;19:1-11 CrossRef Medline

28. Forster DM, Steiner L, Hakanson S, et al. The value of repeat panangiography in cases of unexplained subarachnoid hemorrhage. J Neurosurg 1978;48:712-16 CrossRef Medline

29. Ildan F, Tuna M, Erman T, et al. Prognosis and prognostic factors in nonaneurysmal perimesencephalic hemorrhage: a follow-up study in 29 patients. Surg Neurol 2002;57:160-65; discussion 165-66 CrossRef Medline

30. Ildan F, Tuna M, Erman T, et al. Prognosis and prognostic factors for unexplained subarachnoid hemorrhage: review of $\mathbf{8 4}$ cases. Neurosurgery 2002;50:1015-24; discussion 1024-25 CrossRef Medline

31. Matsumaru Y, Yanaka K, Muroi A, et al. Significance of a small bulge on the basilar artery in patients with perimesencephalic nonaneurysmal subarachnoid hemorrhage: report of two cases. J Neurosurg 2003;98:426-29 CrossRef Medline

32. Alexander MS, Dias PS, Uttley D. Spontaneous subarachnoid hemorrhage and negative cerebral panangiography: review of 140 cases. J Neurosurg 1986;64:537-42 CrossRef Medline

33. Watanabe A, Hirano K, Kamada M, et al. Perimesencephalic nonaneurysmal subarachnoid haemorrhage and variations in the veins. Neuroradiology 2002;44:319-25 CrossRef Medline

34. Wijdicks EF, Schievink WI. Perimesencephalic nonaneurysmal subarachnoid hemorrhage: first hint of a cause? Neurology 1997;49: 634-36 CrossRef Medline

35. Tatter SB, Buonanno FS, Ogilvy CS. Acute lacunar stroke in association with angiogram-negative subarachnoid hemorrhage: mechanistic implications of two cases. Stroke 1995;26:891-95 CrossRef Medline

36. Yamakawa $\mathrm{H}$, Ohe $\mathrm{N}$, Yano $\mathrm{H}$, et al. Venous drainage patterns in perimesencephalic nonaneurysmal subarachnoid hemorrhage. Clin Neurol Neurosurg 2008;110:587-91 CrossRef Medline

37. Kawamura $Y$, Narumi $O$, Chin $M$, et al. Variant deep cerebral venous drainage in idiopathic subarachnoid hemorrhage. Neurol Med Chir (Tokyo) 2011;51:97-100 CrossRef Medline

38. van der Schaaf IC, Velthuis BK, Gouw A, et al. Venous drainage in perimesencephalic hemorrhage. Stroke 2004;35:1614-18 CrossRef Medline

39. Song JH, Yeon JY, Kim KH, et al. Angiographic analysis of venous drainage and a variant basal vein of Rosenthal in spontaneous idiopathic subarachnoid hemorrhage. J Clin Neurosci 2010;17:1386-90 CrossRef Medline

40. Alén JF, Lagares A, Campollo J, et al. Idiopathic subarachnoid hemorrhage and venous drainage: are they related? Neurosurgery 2008; 63:1106-11; discussion 1111-12 CrossRef Medline

41. Buyukkaya R, Yildirim N, Cebeci $\mathrm{H}$, et al. The relationship between perimesencephalic subarachnoid hemorrhage and deep venous system drainage pattern and calibrations. Clin Imaging 2014;38: 226-30 CrossRef Medline

42. DerSimonian R, Laird N. Meta-analysis in clinical trials. Contro Clin Trials 1986;7:177-88 CrossRef Medline

43. Higgins JP, Thompson SG, Deeks JJ, et al. Measuring inconsistency in meta-analyses. BMJ 2003;327:557-60 CrossRef Medline

44. Deeks JJ, Dinnes J, D'Amico R, et al. Evaluating non-randomised intervention studies. Health Technol Assess 2003;7:iii-x, 1-173 Medline

45. Wolf BS, Huang YP, Newman CM. The lateral anastomotic mesencephalic vein and other variations in drainage of the basal cerebral vein. Am J Roentgenol Radium Ther Nucl Med 1963;89:411-22 Medline

46. Chung JI, Weon YC. Anatomic variations of the deep cerebral veins, tributaries of basal vein of Rosenthal: embryologic aspects of the regressed embryonic tentorial sinus. Interv Neuroradiol 2005;11: 123-30 Medline

47. Huang YP, Wolf BS. The basal cerebral vein and its tributaries. In Newton TH, Potts DG, eds. Radiology of the Skull and Brain: Angiography. Vol 2. St Louis: Mosby; 1974:2111-54

48. Padget $\mathrm{DH}$. The cranial venous system in man in reference to development, adult configuration, and relation to the arteries. Am J Anat 1956;98:307-55 CrossRef Medline

49. Tubbs RS, Loukas M, Louis RG Jr, et al. Surgical anatomy and landmarks for the basal vein of Rosenthal. J Neurosurg 2007;106:900-02 CrossRef Medline

50. San Millán D, Gailloud P, Rüfenacht DA, et al. The craniocervical 
venous system in relation to cerebral venous drainage. AJNR Am J Neuroradiol 2002;23:1500-08 Medline

51. Matsumaru Y, Yanaka K, Matsumura A. Is perimesencephalic nonaneurysmal hemorrhage of venous origin? Stroke 2004;35:2753-54; author reply 2754 Medline

52. Greebe P, Rinkel GJ. Life expectancy after perimesencephalic subarachnoid hemorrhage. Stroke 2007;38:1222-24 CrossRef Medline

53. Kalra VB, Wu X, Matouk CC, et al. Use of follow-up imaging in isolated perimesencephalic subarachnoid hemorrhage: a metaanalysis. Stroke 2015;46:401-06 CrossRef Medline

54. Kapadia A, Schweizer TA, Spears J, et al. Nonaneurysmal perimesencephalic subarachnoid hemorrhage: diagnosis, pathophysiol- ogy, clinical characteristics, and long-term outcome. World Neurosurg 2014;82:1131-43 CrossRef Medline

55. Naidech AM, Rosenberg NF, Maas MB, et al. Predictors of hemorrhage volume and disability after perimesencephalic subarachnoid hemorrhage. Neurology 2012;78:811-15 CrossRef Medline

56. Kong Y, Zhang JH, Qin X. Perimesencephalic subarachnoid hemorrhage: risk factors, clinical presentations, and outcome. Acta Neurochir Suppl 2011;110(pt 1):197-201 CrossRef Medline

57. Daenekindt T, Wilms G, Thijs V, et al. Variants of the basal vein of Rosenthal and perimesencephalic nonaneurysmal hemorrhage. Surg Neurol 2008;69:526-29; discussion 529 CrossRef Medline 